\title{
KEANEKARAGAMAN JENIS ANGGREK ALAM (Orchidaceae) BERDASARKAN KETINGGIAN TEMPAT DI GUNUNG POTENG CAGAR ALAM RAYA PASI KOTA SINGKAWANG PROVINSI KALIMANTAN BARAT
}

(The Diversity of Natural Orchid Species (Orchidaceae) Based on the Altitudes in Mount Poteng Raya Pasi Nature Reserve Singkawang City West Kalimantan Province)

\author{
Novita Putri Sesar, Iskandar, Togar Fernando Manurung \\ Fakultas Kehutanan Universitas Tanjungpura Pontianak. Jl. Daya Nasional Pontianak 78124 Email: \\ novitaputrisesar27@gmail.com
}

\begin{abstract}
Natural orchids are one of the flora in Mount Poteng which is included of Raya Pasi Nature Reserve located at Singkawang City, West Kalimantan Province. Orchids have economic value for source of income and be beneficial to ecology that needs to be protected. The altitudes and environmental factors strongly affected the presence of orchid species. The research aims to record the diversity of natural orchids species based on the altitudes place in Mount Poteng. The research was conducted on February 28 until March 28, 2020. This research uses survey method. The research sample was taken using double plots method and to determine sample plots locations is conducted by purposive. The total number of the sample plots is 16 plots and each plot measure 20 by 50 meters. Based on the result of research found 19 species of natural orchids that consist of 348 individuals. The results analysis of the diversity index of orchid species in whole of altitudes at Mount Poteng is 1,338 that is included medium range. The highest species diversity index of 1,300 occurred at altitude of 400-500 $m$ asl and the lowest species diversity index at altitude of 700-725 $\mathrm{m}$ asl that is 0,594. Orchid species which found in whole of altitudes is Dendrobium crumenatum. Furthermor, there were found the orchid species on certain heights are Cleisostoma scortechinii, Cordiglottis filiformis, Ludisia discolor, and Phalaenopsis pantherina at altitude of $400-500 \mathrm{~m}$ asl and species of Bromheadia finlaysoniana and Pomatocalpa latifolia found at altitude of 700-725 $\mathrm{m}$ asl.
\end{abstract}

Keywords: altitudes, mount poteng, orchids, species diversity

\section{PENDAHULUAN}

Hutan merupakan kawasan penyedia sumber daya alam hayati yang memiliki keanekaragaman jenis tumbuhan dan satwa. Tanaman anggrek merupakan salah satu flora yang termasuk dalam family Orchidaceae yang memiliki nilai potensial. Secara ekologi keberadaan anggrek dapat dijadikan indikator terhadap kondisi suatu kawasan hutan sedangkan secara ekonomi anggrek bernilai jual karena memiliki perawakan bentuk bunga yang beragam serta warna yang menarik. Pemanfaatan anggrek lainnya adalah sebagai obat herbal dan bahan campuran pembuatan minyak wangi.
Tanaman anggrek dapat hidup pada berbagai ketinggian tempat mulai dari pesisir hingga pegunungan. Beberapa jenis anggrek dapat tumbuh dan berbunga di daerah dataran tinggi sedangkan beberapa jenis lainnya dapat hidup di daerah dataran rendah hingga medium. Pada dataran tinggi keanekaragaman hayati lebih rendah dibanding dengan dataran rendah. Semakin berkurangnya ketinggian suatu tempat, maka kelimpahan jenis akan bertambah secara bertahap. Faktor lain yang mempengaruhi kekayaan jenis pada tingkat habitat adalah iklim dan kesuburan tanah (Indrawan, 2007).

Gunung Poteng termasuk dalam kawasan Cagar Alam Raya Pasi Kota 
Singkawang yang memiliki ketinggian \pm 725 meter di atas permukaan laut yang. Di Gunung Poteng terdapat berbagai jenis tumbuhan dan satwa liar, diantaranya adalah jenis-jenis anggrek alam. Kemudahan aksesibilitas untuk menjangkau kawasan Gunung Poteng menjadi peluang masuknya masyarakat untuk melakukan eksploitasi anggrek alam sehingga menyebabkan kerusakan habitat anggrek dan berkurangnya keanekaragaman jenis anggrek alam. Gunung Poteng merupakan kawasan konservasi yang berfungsi sebagai salah satu habitat anggrek yang perkembangannya berlangsung secara alami sehingga penelitian mengenai keanekaragaman jenis anggrek di Gunung Poteng perlu dilakukan untuk meninjau keberadaan anggrek alam. Tujuan dari penelitian ini adalah untuk mendata keanekaragaman jenis anggrek alam berdasarkan ketinggian tempat di Gunung Poteng. Hasil penelitian diharapkan dapat memberi manfaat berupa informasi mengenai jenis-jenis anggrek alam dan nilai keanekaragamannya berdasarkan ketinggian tempat di Gunung Poteng yang dapat digunakan sebagai acuan dalam pengelolaan kawasan oleh pihak Cagar Alam Raya Pasi dan literatur untuk penelitian selanjutnya.

\section{METODE PENELITIAN}

Penelitian ini dilaksanakan di Gunung Poteng yang termasuk dalam kawasan Cagar Alam Raya Pasi Kota Singkawang. Penelitian dilaksanakan pada 28 Februari s.d 28 Maret 2020. Objek penelitian adalah semua jenis anggrek alam yang terdapat pada petak pengamatan berdasarkan ketinggian tempat di Gunung Poteng
Data yang dikumpulkan merupakan data primer dan data sekunder. Data primer meliputi ketinggian tempat, jumlah jenis dan jumlah individu dari masingmasing jenis, tempat tumbuh anggrek, pengukuran suhu dan kelembapan udara, intensitas cahaya matahari serta $\mathrm{pH}$ tanah dalam petak contoh pada masing-masing ketinggian tempat. Data sekunder terkait status kawasan, keadaan umum lokasi, tipe iklim, topografi dan jenis tanah, serta aksesibilitas.

Penelitian ini menggunakan metode survei dengan cara petak ganda melalui jalan utama yang sudah ada. Penentuan petak contoh dilakukan secara purposive berdasarkan keberadaan anggrek setelah melakukan orientasi lapangan. Petak contoh berukuran $20 \mathrm{~m}$ x $50 \mathrm{~m}$ dengan luas 0,1 ha. Petak contoh dibuat pada ketinggian tempat yang berbeda, yaitu pada ketinggian 200-300 $\mathrm{m}$ dpl dibuat 1 petak contoh, ketinggian 300-400 m dpl dibuat 2 petak contoh, ketinngian 400-500 $\mathrm{m}$ dpl dibuat 10 petak contoh, ketinggian 600-700 m dpl dibuat 1 petak contoh, dan ketinggian 700-725 m dpl dibuat 2 petak contoh, sehingga terdapat 16 petak contoh dengan luas total pengamatan adalah 1,6 ha.

Identifikasi jenis anggrek alam yang telah ditemukan di Gunung Poteng dilakukan dengan mengamati bagian morfologi anggrek kemudian mencocokkan data morfologi yang diperoleh dengan deskripsi dalam buku identifikasi Anggrek Spesies Kalimantan Barat Volume 1 (Siregar et al. 2005).

Analisis data hasil penelitian diolah secara kuantitatif dilakukan dengan cara menghitung indeks nilai penting, indeks 
dominansi, indeks kekayaan jenis, indeks keanekaragaman jenis, indeks kelimpahan jenis, dan indeks kesamaan jenis

\section{HASIL DAN PEMBAHASAN}

Hasil penelitian terhadap anggrek alam di kawasan Gunung Poteng berdasarkan ketinggian tempat yang berbeda, yaitu ketinggian 200-300 m dpl, 300-400 m dpl, 400-500 m dpl, 600-700 m dpl, dan 700-725 m dpl ditemukan 19 jenis dengan jumlah seluruh jenis sebanyak 348 individu dapat dilihat pada tabel 1 .

Tabel 1. Jumlah individu (N) jenis-jenis anggrek alam berdasarkan ketinggian di Gunung Poteng (The number of individuals $(N)$ natural orchid species based on the altitudes in Mount Poteng)

\begin{tabular}{|c|c|c|c|c|c|c|c|}
\hline \multirow[t]{2}{*}{ No } & \multirow[t]{2}{*}{ Jenis } & \multicolumn{5}{|c|}{ Ketinggian Tempat (m dpl) } & \multirow[t]{2}{*}{ Total } \\
\hline & & 200-300 & $300-400$ & $400-500$ & $600-700$ & $700-725$ & \\
\hline 1 & Acriopsis liliifolia & - & - & 49 & 4 & 2 & 55 \\
\hline 2 & Aerides odorata & - & 5 & 22 & - & 1 & 28 \\
\hline 3 & Bromheadia finlaysoniana & - & - & - & - & 4 & 4 \\
\hline 4 & Bulbophyllum lepidum & 2 & - & 7 & - & - & 9 \\
\hline 5 & Bulbophyllum sp. & - & 6 & 64 & 5 & 7 & 82 \\
\hline 6 & Bulbophyllum vaginatum & 3 & 3 & 7 & - & - & 13 \\
\hline 7 & Cleisostoma scortechinii & - & - & 4 & - & - & 4 \\
\hline 8 & Coelogyne asperata & - & 2 & 1 & - & - & 3 \\
\hline 9 & Cordiglottis filiformis & - & - & 8 & - & - & 8 \\
\hline 10 & Cymbidium finlaysonianum & 4 & - & 19 & - & 3 & 26 \\
\hline 11 & Dendrobium anosmum & 1 & - & 3 & - & - & 4 \\
\hline 12 & Dendrobium crumenatum & 3 & 9 & 34 & 7 & 5 & 58 \\
\hline 13 & Dendrobium smithianum & - & 1 & 13 & - & - & 14 \\
\hline 14 & Ludisia discolor & - & - & 6 & - & - & 6 \\
\hline 15 & Nervilia uniflora & - & 1 & 2 & - & - & 3 \\
\hline 16 & Phalaenopsis pantherina & - & - & 11 & - & - & 11 \\
\hline 17 & Pomatocalpa latifolia & - & - & - & - & 1 & 1 \\
\hline 18 & Renanthera elongata & - & 3 & - & 1 & - & 4 \\
\hline 19 & Thrixspermum centipeda & - & 2 & 13 & - & - & 15 \\
\hline & Total & 13 & 32 & 263 & 17 & 23 & 348 \\
\hline
\end{tabular}

Keterangan: - tidak ditemukan anggrek alam

Jenis anggrek paling banyak ditemukan pada ketinggian 400-500 m dpl sebanyak 16 jenis dengan jumlah 263 individu dan jenis anggrek paling sedikit ditemukan pada ketinggian 600-700 m dpl sebanyak 4 jenis dengan jumlah 17 individu. Perbedaan jenis anggrek alam yang dijumpai disebabkan oleh faktor fisiografi yang berkaitan dengan ketinggian tempat dan bentuk wilayah (Pranata, 2005). Perbedaan ketinggian memberikan perbedaan yang nyata pada iklim dan variasi ekologi (Sarmiento, 1986).

Lokasi penelitian pada ketinggian 400$500 \mathrm{~m}$ dpl memiliki tutupan tajuk pohon yang relatif rapat, namun yang masih dapat ditembus cahaya matahari. Keadaan ini sesuai yang dikemukakan oleh Febriliani et al. (2013) bahwa energi cahaya tersebut memberikan pengaruh terhadap anggrek alam dalam proses fotosintesis, pertumbuhan, perkecambahan dan pembungaannya. Oleh karena itu, struktur dan keanekaragaman jenis vegetasi tegakan pohon di lokasi penelitian juga berpengaruh terhadap jenis-jenis anggrek yang ada, khususnya bagi anggrek anggrek epifit dan terrrestrial yang mutlak memerlukan naungan. Anggrek alam yang ditemukan pada ketinggian 400-500 m dpl 
lebih bervariasi dalam jumlah jenis maupun jumlah individu dibandingkan dengan ketinggian lainnya, hal ini menandakan kondisi hutan yang baik dan iklim mikro yang mendukung pertumbuhan anggrek pada ketinggian ini.

Anggrek Dendrobium crumenatum memiliki tingkat penyesuaian paling baik dibandingkan dengan jenis-jenis anggrek alam lainnya karena dapat ditemuakan pada semua ketinggian tempat. Hal ini membuktikan D. crumenatum mempunyai kemampuan beradaptasi dengan kondisi lingkungan hutan pada ketinggian tempat yang berbeda-beda. Rata-rata suhu udara pada lima tingkat ketinggian berkisar $24,4^{\circ}$ $25,2^{\circ} \mathrm{C}$ dan sesuai dengan pernyataan Siregar (2005), bahwa $D$. crumenatum dapat tumbuh baik pada suhu udara antara $23^{\circ}-31^{\circ} \mathrm{C}$.

Anggrek Cleisostoma scortechinii, Cordiglottis filiformis, Ludisia discolor, dan Phalaenopsis pantherina ditemukan hanya tumbuh pada ketinggian 400-500 m dpl. Kondisi permukaan tanah pada ketinggian 400-500 m dpl yang lembab dan penuh dengan humus serasah dapat mendukung sebagai tempat hidup jenis anggrek terestrial, seperti Ludisia discolor yang tumbuh di lantai hutan. Menurut Siregar (2005), iklim mikro untuk pertumbuhan Cleisostoma scortechinii dan Phalaenopsis pantherina dapat tumbuh baik dengan suhu udara antara $23^{\circ}-26^{\circ} \mathrm{C}$ sedangkan Cordiglottis filiformis memiliki kebutuhan cahaya sebesar $50 \%$, pernyataan tersebut sesuai dengan kondisi tutupan tajuk pohon yang masih dapat ditembus cahaya matahari dan suhu udara harian yang tercatat $24,5^{\circ} \mathrm{C}$ pada ketinggian tersebut.

Anggrek Bromheadia finlaysoniana dan Pomatocalpa latifolia ditemukan hanya tumbuh pada ketinggian 700-725 m dpl, kedua jenis tersebut memiliki toleran terhadap kondisi vegetasi yang terbuka dengan tanah yang cenderung kering. Siregar (2005) menyatakan bahwa B. finlaysoniana dan $P$. latifolia masing-masing membutuhkan intensitas cahaya sebesar $75 \%$ dan $100 \%$, oleh karena itu kondisi fisik lingkungan dan faktor abiotik pada setiap ketinggian tempat berkaitan dengan variasi jenis anggrek alam yang dijumpai disebabkan masing-masing jenis anggrek mempunyai syarat tumbuh optimal.

\section{Indeks Nilai Penting (INP)}

Hasil penelitian dari 16 petak pengamatan ditemukan jenis yang paling dominan dari 19 jenis tersebut adalah Acriopsis liliifolia, Bulbophyllum sp., dan Dendrobium crumenatum dengan masingmasing nilai INP lebih besar dari $8 \%$. Jenis Acriopsis liliifolia ditemukan hidup mulai pada ketinggian $400 \mathrm{~m}$ dpl ke atas, jenis Bulbophyllum sp ditemukan hidup mulai pada ketinggian $300 \mathrm{~m}$ dpl ke atas, dan jenis Dendrobium crumenatum ditemukan hidup pada semua ketinggian. Berdasarkan hasil tersebut menunjukkan bahwa 3 jenis anggrek alam tersebut memiliki kemampuan adaptasi yang cukup baik terhadap perbedaan ketinggian tempat dan faktor abiotik tempat tumbuhnya.

Anggrek alam yang ditemukan pada ketinggian 200-300 m dpl secara keseluruhan terdapat 5 jenis dengan jumlah seluruh individu sebanyak 13 individu dan jenis anggrek yang dominan adalah Cymbidium finlaysonianum dengan INP 13,248\%. Ketinggian 300-400 m dpl ditemukan 9 jenis dengan jumlah seluruh individu sebanyak 32 individu dan jenis anggrek yang dominan adalah Dendrobium crumenatum dengan INP 13,462\%. Ketinggian 400-500 m dpl 
ditemukan 16 jenis dengan jumlah seluruh individu sebanyak 263 individu dan jenis anggrek yang dominan adalah Bulbophyllum sp. dengan INP 13,601\%. Ketinggian 600$700 \mathrm{~m}$ dpl ditemukan 4 jenis dengan jumlah individu sebanyak 17 individu dan jenis anggrek yang dominan adalah Dendrobium crumenatum dengan INP 24,573\%. Ketinggian 700-725 m dpl ditemukan 7 jenis dengan jumlah seluruh individu sebanyak 23 individu dan jenis anggrek yang dominan $16,310 \%$. Jenis-jenis yang dominan tersebut memiliki jumlah kehadiran individu lebih besar dibandingkan dengan jenis yang lain.

Perbedaan jenis-jenis anggrek dan INP pada setiap ketinggian tersebut menunjukkan bahwa ketinggian tempat yang berbeda berkaitan dengan perubahan iklim mikro tempat tumbuh anggrek alam, sehingga berpengaruh terhadap penyebaran jenis-jenis anggrek dan pertumbuhannya. Jenis yang penyebarannya terbatas kemungkinan juga dipengaruhi oleh sifat toleransi jenis anggrek tersebut terhadap ketinggian.

\section{Indeks Dominansi (C)}

Tingkat dominansi jenis anggrek alam pada setiap ketinggian tempat tergolong rendah karena hasil perhitungan nilai (C) kurang dari 1. Nilai (C) tertinggi pada ketinggian 700-725 $\mathrm{m}$ dpl sebesar 0,469 adalah Bulbophyllum sp. dengan INP

karena ditemukan kehadiran jenis Bulbophyllum sp. dengan INP 16,310\%, dimana INP tersebut lebih tinggi dibandingkan INP dari jenis-jenis lainnya yang hanya di bawah $10 \%$. Nilai (C) untuk seluruh ketinggian tempat adalah sebesar 0,064 menunjukkan bahwa dalam kawasan Gunung Poteng tidak hanya dikuasi oleh satu jenis tetapi masih terdapat beberapa jenis yang mendominasi dalam kawasan tersebut dan pola dominansinya cenderung menyebar.

Indeks Keanekaragaman Jenis (H')

$\begin{array}{lrr}\quad \text { Soegianto } & (1994) & \text { menyatakan } \\ \text { keanekaragaman } & \text { jenis } & \text { merupakan } \\ \text { karakteristik } & \text { tingkatan } & \text { komunitas }\end{array}$
berdasarkan organisasi biologinya, sedangkan indeks keanekaragaman adalah nilai yang menunjukkan tinggi rendahnya keanekaragaman populasi dari jenis-jenis yang berbeda di dalam komunitas. Keanekaragaman jenis anggrek dapat terukur dari hasil perhitungan indeks dominansi (C), indeks kekayaan jenis (D), indeks keanekaragaman jenis (H'), dan indeks kelimpahan atau kemerataan jenis (E), dimana indeks-indeks tersebut berkaitan dengan INP dari jenis-jenis anggrek yang diamati. Jenis-jenis yang mempunyai INP tinggi berpengaruh terhadap kestabilan komunitas karena bersifat dominan diantara jenis lainnya.

Tabel 2. Daftar indeks dominansi (C), indeks kekayaan jenis (D), indeks keanekaragaman jenis (H'), dan indeks kelimpahan jenis (E) pada berbagai ketinggian di Gunung Poteng (List of species dominances index, species richness index, species diversity index, and species abundance index based on the altitudes in Mount Poteng)

\begin{tabular}{cccccc}
\hline No & Ketinggian Tempat & C & D & H' & E \\
\hline 1 & $200-300 \mathrm{~m}$ dpl & 0,108 & 6,461 & 1,025 & 1,468 \\
2 & $300-400 \mathrm{~m}$ dpl & 0,091 & 9,119 & 1,161 & 1,429 \\
3 & $400-500 \mathrm{~m}$ dpl & 0,071 & 11,537 & 1,300 & 0,979 \\
4 & $600-700 \mathrm{~m}$ dpl & 0,132 & 4,662 & 0,904 & 1,125 \\
5 & $700-725 \mathrm{~m}$ dpl & 0,469 & 5,486 & 0,594 & 0,775 \\
\hline
\end{tabular}


Indeks keanekaragaman jenis tertinggi ada pada ketinggian 400-500 m dpl dengan nilai (H') sebesar 1,300. Nilai (H') pada ketinggian 400-500 m dpl lebih besar dibandingkan dengan ketinggian lainnya karena jumlah jenis yang ditemukan lebih banyak sedangkan hasil perhitungan nilai keanekaragaman jenis anggrek dari kelima ketinggian tempat di kawasan Gunung Poteng adalah 1,338. Nilai tersebut menunjukkan bahwa tingkat keanekaragaman jenis anggrek tergolong sedang karena nilai (H) kurang dari 3 (Shannon dan Wiener, 1949). Miardini et al. (2010) menjelaskan nilai (H') $1 \leq\left(\mathrm{H}^{\prime}\right) \leq 3$ menunjukkan bahwa keanekaragaman jenis pada suatu kawasan adalah sedang, penyebaran jumlah individu tiap jenis sedang dan kestabilan komunitas sedang. Keanekaragaman jenis anggrek yang dikategorikan sedang di kawasan Gunung Poteng disebabkan adanya beberapa jenis anggrek yang mendominasi ditandai dengan INP yang tinggi dan penyebaran jumlah individu pada masing-masing jenis hampir merata. Hal ini diperkuat oleh pernyataan Odum (1996) bahwa nilai keanekaragaman dipengaruhi oleh jumlah jenis yang ditemukan dan pembagian penyebaran individu dalam tiap jenisnya, jika penyebaran individu tidak merata maka nilai keanekaragaman jenis cenderung rendah dan sebaliknya.

Napitupulu (1997) menyatakan nilai keanekaragaman jenis anggrek dapat menjadi salah satu indikator terhadap kondisi suatu kawasan hutan, ditandai dari adanya tegakan vegetasi pohon-pohon besar yang menjadi habitat alami anggrek epifit yang tidak dapat tergantikan oleh unsur-unsur lainnya maupun bagi anggrek terrestrial yang sebagian besar hidupnya memerlukan naungan. Menurut
Istiati (2009) anggrek dapat tumbuh optimal pada suhu $13^{\circ}-30^{\circ} \mathrm{C}$ dan Comber (1990) menambahkan bahwa pada dasarnya anggrek memiliki syarat kelembapan udara optimum 50-100\%. Pernyataan tersebut sesuai dengan kondisi rata-rata suhu udara pada lima tingkat ketinggian di kawasan Gunung Poteng berkisar $24,4^{\circ}-25,2^{\circ} \mathrm{C}$ dan rata-rata kelembapan udara berkisar 84,0-92,3\% oleh karena itu keberadaan anggrek di kawasan Gunung Poteng menandakan kondisi hutan yang masih relatif baik.

Indeks keanekaragaman jenis anggrek alam berdasarkan ketinggian tempat di Gunung Poteng termasuk dalam kategori rendah hingga sedang sementara kondisi hutan Gunung Poteng masih relatif baik, hal ini dapat tercermin dari indeks similaritas yang menunjukkan bahwa jenis-jenis anggrek alam yang ada pada tiga ketinggian tempat, yaitu 200-300 m dpl, 300-400 m dpl, dan 400-500 m dpl memiliki kemiripan antara satu dengan yang lain. Kemiripan komposisi jenis antara ketiga ketinggian tersebut dipengaruhi oleh kondisi lingkungan abiotik yang tidak berbeda jauh karena kondisi hutan yang masih relatif baik, namun pada ketinggian 200-300 m dpl memiliki nilai (H') tergolong sedang sebesar 1,025, di mana nilai tersebut lebih kecil dibandingkan pada ketinggian 300-400 m dpl dan 400-500 m dpl. Rendahnya nilai ( $\left.\mathrm{H}^{\prime}\right)$ pada ketinggian 200-300 m dpl disebabkan adanya jalan setapak yang memudahkan setiap orang untuk memasuki kawasan tanpa mendapat pengawasan sehingga membuka peluang terjadinya perambahan anggrek alam mengingat meningkatnya kegemaran masyarakat mengoleksi tanaman hias serta anggrek alam yang bernilai ekonomi tinggi 
membuat masyarakat di sekitar hutan mencari dan menjualnya.

Indeks keanekaragaman jenis anggrek dalam kategori rendah terjadi pada ketinggian 600-700 m dpl dan 700-725 m dpl, hal ini sesaui dengan hasil indeks similaritas yang menunjukkan komposisi jenis anggrek alam yang dibandingkan antar ketinggian terhadap masing-masing ketinggian 600-700 m dpl dan 700-725 m dpl memiliki perbedaan. Adanya perbedaan komposisi jenis anggrek alam disebabkan keadaan vegetasi hutan cenderung terbuka seiring dengan bertambahnya ketinggian tempat. Di lapangan terlihat struktur pepohonan membentuk tajuk yang semakin ke atas akan semakin pendek, tajuk rata, batang dan cabang berlekuk, serta morfologi daun yang tebal dan kecil, kondisi demikian mengakibatkan penetrasi cahaya lebih banyak pada lantai hutan sehingga ditumbuhi vegetasi berbentuk semak-semak rendah. Perubahan struktur pepohonan mempengaruhi faktor abiotik lingkungan tempat tumbuh anggrek alam dan berkurangnya komposisi vegetasi pohonpohon sebagai inang anggrek juga turut berpengaruh terhadap keberadaan anggrek alam.

Keanekaragaman jenis anggrek di kawasan Gunung Poteng umumnya berhubungan dengan faktor lingkungan yang memberi pengaruh terhadap vegetasi anggrek, diantaramya ketinggian tempat, intensitas cahaya matahari, suhu dan kelembapan udara serta tersedianya unsur hara yang dapat diserap oleh anggrek untuk mendukung pertumbuhan anggrek. Faktorfaktor lingkungan tersebut dapat menjadi faktor pembatas persebaran jenis-jenis anggrek dan pertumbuhannya dikarenakan syarat tumbuh dan kemampuan adaptasi yang berbeda-beda dari masing-masing jenis anggrek. Selain itu, berkurangnya populasi anggrek alam dapat pula disebabkan kemudahakan memasuki kawasan Gunung Poteng, sehingga menjadi peluang pengambilan anggrek alam untuk dimanfaatkan secara ekonomi oleh masyarakat sekitar kawasan.

\section{Indeks Kekayan Jenis (D)}

Indeks kekayaan jenis tertinggi terjadi pada ketinggian 400-500 m dpl sebesar 11,537. Tingginya nilai (D) seiring dengan penambahan jumlah jenis dan individu yang ditemukan pada lokasi pengamatan, hal ini juga menunjukkan bahwa kondisi tempat tumbuh pada ketinggian tersebut ideal untuk pertumbuhan anggrek ditandai dari jenis anggrek yang ditemukan lebih beragam.

\section{Indeks Kelimpahan Jenis (E)}

Hasil analisa data dari tiap ketinggian tempat di kawasan Gunung Poteng dapat disimpulkan bahwa kelimpahan jenisnya melimpah. Hal ini terlihat dari indeks (E) pada masing-masing ketinggian tempat tersebut rata-rata hampir 1. Nilai (E) mendekati 1 menunjukkan hampir seluruh jenis yang ada mempunyai kelimpahan yang relatif sama (Odum, 1993).

Indeks kelimpahan jenis anggrek dari seluruh ketinggian tempat sebesar 0,924. Tingginya nilai kelimpahan jenis berkaitan dengan indeks keanekaragaman jenis yang cukup stabil. Soegianto (1994) menyatakan bahwa suatu komunitas cenderung memiliki keanekaragaman tinggi jika disusun oleh banyak jenis dengan kelimpahan jenis yang sama atau hampir sama. Indeks keanekaragaman jenis anggrek di kawasan Gunung Poteng tergolong sedang, sehingga kelimpahan jenis anggrek terdistribusi relatif 
merata dalam jumlah individu yang cukup melimpah.

Indeks Kesamaan Jenis Anggrek (IS)
Hasil perhitungan indeks kesamaan jenis anggrek antara dua ketinggian tempat yang dibandingkan dapat dilihat pada tabel 3 .

Tabel 3. Daftar indeks kesamaan jenis (IS) berdasarkan perbandingan jumlah jenis antar ketinggian di Gunung Poteng (List of species similarity index based on comparison the number of species among the altitudes in Mount Poteng)

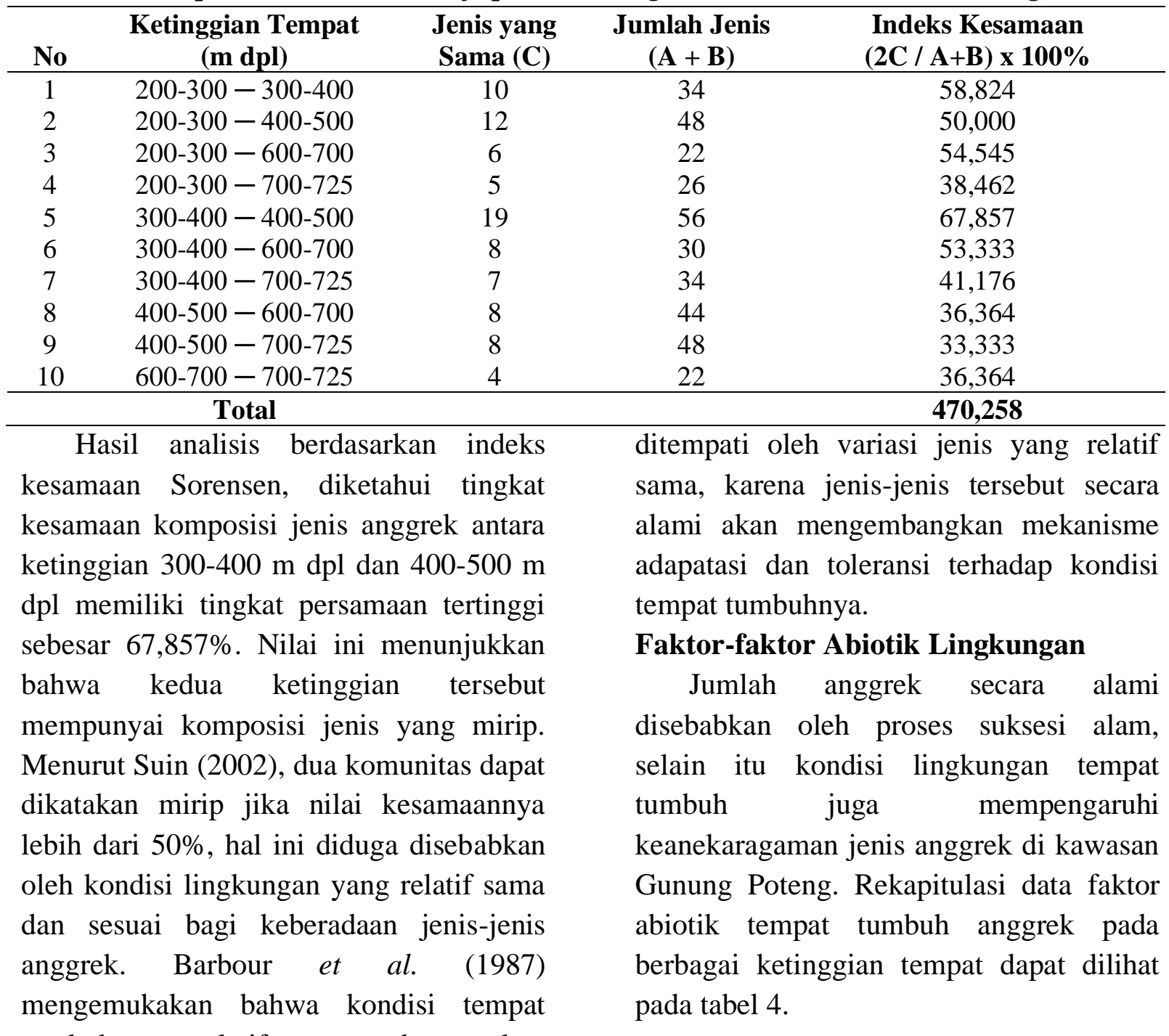

tumbuh yang relatif sama cenderung akan

Tabel 4. Hasil rata-rata pengukuran faktor abiotik pada berbagai ketinggian di Gunung Poteng (Average results of measurement abiotic factors in various altitudes in Mount Poteng)

\begin{tabular}{lccccc}
\hline \multicolumn{1}{c}{ Faktor Abiotik } & \multicolumn{5}{c}{ Ketinggian Tempat (m dpl) } \\
\cline { 2 - 6 } & $\mathbf{2 0 0 - 3 0 0}$ & $\mathbf{3 0 0 - 4 0 0}$ & $\mathbf{4 0 0 - 5 0 0}$ & $\mathbf{6 0 0 - 7 0 0}$ & $\mathbf{7 0 0 - 7 2 5}$ \\
\hline Suhu Udara $\left({ }^{\circ} \mathrm{C}\right)$ & 24,9 & 24,4 & 24,5 & 25,1 & 25,2 \\
Kelembapan Udara $(\%)$ & 89,3 & 90,7 & 92,3 & 86,3 & 84,0 \\
Suhu Tanah $\left({ }^{\circ} \mathrm{C}\right)$ & 24 & 24 & 23,3 & 26 & 28,3 \\
pH Tanah & 6,2 & 6,3 & 7,0 & 7,3 & 7,3 \\
Intensitas Cahaya (lux) & 242,7 & 236,3 & 225,7 & 1331,0 & 5022,3 \\
\hline
\end{tabular}


Suhu udara, suhu tanah, dan intensitas cahaya cenderung meningkat seiring bertambahnya ketinggian tempat dikarenakan kondisi kawasan yang semakin terbuka, sehingga intensitas cahaya matahari masuk ke lantai hutan lebih banyak dan menyebabkan kelembaban udara cenderung menurun, sedangkan $\mathrm{pH}$ tanah mengalami peningkatan setiap naiknya ketinggian tempat, peningkatan $\mathrm{pH}$ dapat disebabkan ketersediaan kation basa yang mendominasi dalam tanah (Marsono dan Sigit, 2005).

Hasil pengamatan pada suhu udara dan suhu tanah lebih rendah pada ketinggian 400$500 \mathrm{~m} \mathrm{dpl}$, hal ini disebabkan banyaknya pohon dengan tajuk yang cukup rimbun dapat mengurangi intensitas cahaya matahari yang masuk, sehingga kelembaban udara meningkat. Kawasan yang memiliki suhu relatif rendah dan kelembapan yang tinggi sangat memungkinkan tumbuhan anggrek dapat tumbuh dan berkembang optimal (Comber, 1990). Selain itu, pH tanah berperan dalam menentukan mudah tidaknya unsur-unsur hara diserap oleh tumbuhan. Unsur hara pada umumnya dapat diserap dengan baik oleh tumbuhan pada $\mathrm{pH}$ netral (Gunawan et al. 2019). Hal ini terbukti dari jumlah jenis anggrek alam lebih banyak ditemukan pada ketinggian 400-500 m dpl yang memiliki pH netral, yaitu 7,0.

\section{Tempat Tumbuh Anggrek}

Anggrek alam yang ditemukan didominasi oleh anggrek epifit yang menumpang hidup di pohon inang untuk mendapatkan cahaya dan sirkulasi udara yang baik. Pohon inang tempat tumbuh anggrek epifit di lokasi penelitian, diantaranya jenis pohon bintangur (Calophyllum inophyllum), keruing (Dipterocarpus oblongifolius), durian (Durio zibethinus), ubah (Eugenia sp.), medang (Litsea angulata), asam (Mangifera sp.), tengkawang (Shorea pinanga), meranti (Shorea sp.), laban (Vitex pubescens), dan beberapa pohon lain yang tidak diketahui jenisnya.

Anggrek epifit terlihat menempel pada pohon inang yang memilik batang bertekstur kasar, beralur, dan retak-retak. Menurut Puspitaningtyas (2007) pohon inang yang memiliki celah pada permukaan kulit pohon akan menahan air lebih baik dan memungkinkan biji anggrek mudah tersangkut serta tumbuh. Ewusie (1990) menambahkan bahwa anggrek epifit menyukai permukaan kulit kayu yang tebal dan kasar, dimana kondisi fisik tersebut akan membantu perekatan akar-akar anggrek pada permukaan kulit batang pohon.

Anggrek terestrial jenis Ludisia discolor menyukai habitat tempat tumbuh yang ternaungi dan jenis Nervilia uniflora cenderung menyukai habitat tempat tumbuh yang agak terbuka karena memiliki kebutuhan cahaya matahari yang sedang sebesar 50\% sedangkan jenis Bromheadia finlaysoniana dapat tumbuh optimal di tempat yang menerima cahaya penuh karena memiliki kebutuhan cahaya mencapai $75 \%$ (Siregar, 2005). Selain itu ditemukan anggrek litofit jenis Dendrobium crumenatum yang tumbuh di atas batu berlumut, keberadaan lumut tersebut memacu kesuburan dan menjaga kelembapan air. Hal ini sesuai dengan pernyataan Selviana et al. (2019) yang mengemukakan Dendrobium crumenatum merupakan anggrek epifit, namun terkadang dapat dijumpai hidup sebagai anggrek litofit yang tumbuh pada substrat bebatuan. Syarat tumbuh tersebut menjadi faktor pembatas persebaran jenisjenis anggrek. 


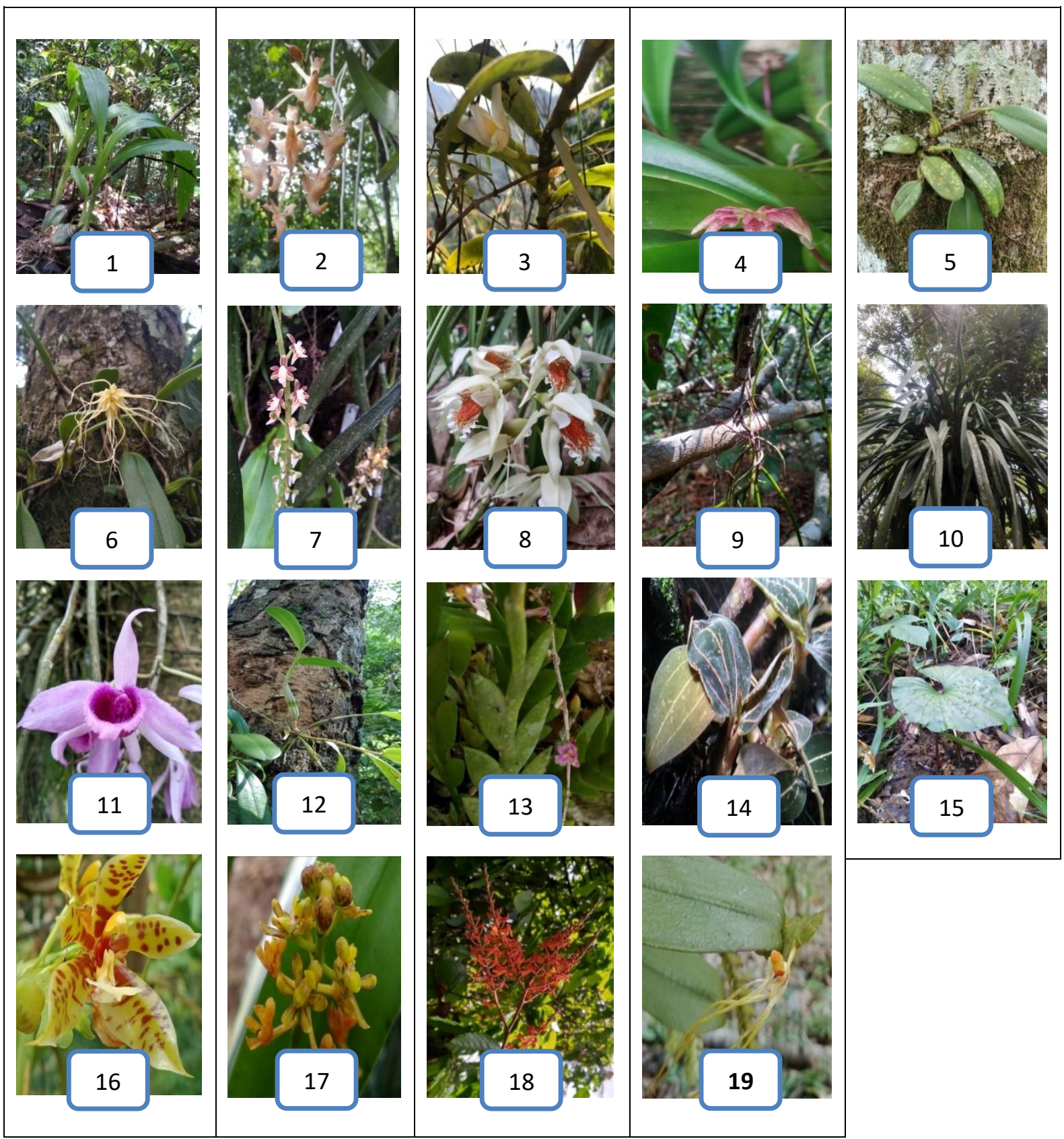

Gambar 1. Jenis-jenis anggrek alam yang ditemukan pada berbagai ketinggian tempat di Gunung Poteng (Types of natural orchid species had found in various altitudes in Mount Poteng)

Keterangan: (1) Acriopsis liliifolia, (2) Aërides odorata, (3) Bromheadia finlaysoniana, (4) Bulbophyllum lepidum, (5) Bulbophyllum sp., (6) Bulbophyllum vaginatum, (7) Cleisostoma scortechinii, (8) Coelogyne asperata, (9) Cordiglottis filiformis, (10) Cymbidium finlaysonianum, (11) Dendrobium anosmum, (12) Dendrobium crumenatum, (13) Dendrobium smithianum, (14) Ludisia discolor, (15) Nervilia uniflora (16) Phalaenopsis pantherina, (17) Pomatocalpa latifolia, (18) Renanthera elongata, (19) Thrixspermum centipeda 


\section{KESIMPULAN DAN SARAN}

Hasil penelitian terhadap keanekagaraman anggrek alam berdasarkan ketinggian tempat di Gunung Poteng ditemukan 19 jenis dengan jumlah seluruh individu sebanyak 348 dengan indeks nilai penting anggrek alam tertinggi adalah Acriopsis liliifolia, Bulbophyllum sp., dan Dendrobium crumenatum.

Jenis yang ditemukan ada pada setiap ketinggian tempat adalah Dendrobium crumenatum dan jenis yang hanya ditemukan pada ketinggian tertentu, yaitu pada ketinggian 400-500 $\mathrm{m}$ dpl ditemukan Cleisostoma scortechinii, Cordiglottis filiformis, Ludisia discolor, dan Phalaenopsis pantherina, sedangkan jenis Bromheadia finlaysoniana dan Pomatocalpa latifolia hanya ditemukan pada ketinggian 700-725 m dpl.

Indeks keanekaragaman jenis anggrek pada seluruh ketinggian tempat sebesar 1,338 dikategorikan sedang. Tingkat dominansi jenis anggrek pada seluruh ketinggian tempat sebesar 0,064 dikategorikan rendah. Indeks kekayaan jenis tertinggi pada ketinggian 400-500 m dpl sebesar 11,537. Indeks kelimpahan jenis pada seluruh ketinggian tempat sebesar 0,924 dikategorikan kelimpahan jenisnya melimpah.

Pengukuran rata-rata suhu udara dari lima tingkat ketinggian di Gunung Poteng berkisar $24,4^{\circ}-25,2^{\circ} \mathrm{C}$, kelembapan udara $84-92,3 \%$, suhu tanah $24^{\circ}-28,3^{\circ} \mathrm{C}, \mathrm{pH}$ tanah 6,2-7,3 dan intensitas cahaya matahari 225,7-5022,3 lux.

Penelitian selanjutnya dapat dilakukan pada kawasan gunung-gunung lain yang ada dalam kawasan Cagar Alam Raya Pasi untuk menggali potensi keanekaragaman jenis hayati. Mengatasi penurunan populasi anggrek alam, sebaiknya pihak Cagar Alam Rasa Pasi melakukan pembudidayaan. Anggrek alam hasil pembudidayaan dapat dikembalikan pada habitat aslinya sehingga anggrek alam tidak mengalami kepunahan.

Anggrek alam memiliki manfaat dari segi ekologi dan ekonomi, sehingga pihak Cagar Alam Raya Pasi perlu melakukan penyuluhan kepada masyarakat sekitar kawasan untuk menciptakan kesadaran dan melibatkan partisipasi masyarakat dalam usaha pelestarian dan perlindungan jenisjenis anggrek alam serta habitatnya serta diharapkan pihak Cagar Alam Raya Pasi dapat menambah jumlah petugas dan sarana/prasarana untuk mengamankan kawasan sebagai upaya untuk mengantisipasi tindakan yang berakibat pada perubahan keutuhan kawasan, termasuk pengambilan anggrek alam.

\section{DAFTAR PUSTAKA}

Barbour GM, JK Burk, WD Pitts. 1987. Terrestrial Plant Ecology. 2nd Ed. 157. New York:

Benyamin/Cumming Publishing. Inc. Reading. Maine.

Comber JB. 1990. Orchids of Java. Bangkok: Charoen Silp Press.

Ewusie JY. 1990. Pengantar Ekologi Tropika. Terjemahan Usman Tanudjaya. ITB. Bandung.

Febriliani, Sri Ningsih M, Muslimin. 2013. Analisis Vegetasi Habitat Anggrek di Sekitar Danau

Tambing Kawasan Taman Nasional Lore Lindu. Jurnal Warta Rimba 1(1):

1-9.

Gunawan, Nurheni W, Sri WBR. 2019. Karakteristik Sifat Kimia Tanah dan Status Kesuburan Tanah pada Agroforestri Tanaman Sayuran 


$\begin{array}{llr}\text { Berbasis } & \text { Eucalyptus } & \text { sp. } \\ \text { Jurnal } & \text { Silvikultur } & \text { Tropika } \\ \text { 10(2):63-69. } & & \end{array}$

Indrawan M. 2007. Biologi Konservasi. Jakarta: Yayasan Obor Indonesia.

Istiati. 2009. Terampil Budidaya Anggrek. Jawa Tengah: Sahabat.

Marsono, Sigit. 2005. Pupuk Akar, Jenis dan Aplikasi. Jakarta: Penebar Swadaya.

Miardini A, Boediyono A, Atmoko BD, Harjadi B, Gunawan. 2010. Analisis Kerentanan Tumbuhan Hutan Akibat Perubahan Iklim. Solo: Badan Penelitian dan Pengembangan Hutan.

Napitupulu B. 1997. Pola Tata Ruang Penyebaran Anggrek (Appendicula sp) di Cibodas. Bul.Penelitian Kehutanan. 12(3):183-192.

Odum EP. 1993. Dasar-Dasar Ekologi. Terjemahan oleh Tjahjono Samingan dari buku Fundamentals of Ecology. Yogyakarta: Gadjah Mada University Press.

Odum EP. 1996. Dasar-Dasar Ekologi. Diterjemahkan oleh Tjahjono Samingan. Yogyakarta: Gajah Mada University Press.

Pranata AS. 2005. Panduan Budidaya dan Perawatan Anggrek. Jakarta: Agro Media.
Puspitaningtyas DM. 2007. Inventarisasi Anggrek dan Inangnya di Taman Nasional Meru Betiri-Jawa Timur. Biodiversitas 8(3):210-214.

Sarmiento G. 1986. Ecologically Crucial Features of Climate in High Tropical Mountains. En: Vuilleumier F, Monasterio M. (Eds): High Altitude Tropical Biogeography, Oxford University Press, Oxford.

Selviana, E. Nurtjahya, D. Sulistiarini. 2019. Jenis-jenis Anggrek (Orchidaceae) di Hutan Rawa Gambut Kabupaten Belitung. Floribunda 6(12):72-80.

Shannon CE, Wiener E. 1949. The Mathematical Theory of Communication. The University of Illinois Press: Urbana, IL, USA.

Siregar C, Listiawati A, Purwaningsih. 2005. Anggrek Spesies Kalimantan Barat. Volume ke-1. Pontianak: Lembaga Penelitian dan Pengembangan Pariwisata Kalimantan Barat (LP3-KB).

Soegianto A. 1994. Ekologi Kuantitatif: Metode Analisis Populasi dan Komunitas. Jakarta: Penerbit Usaha Nasional.

Suin NM. 2002. Metoda Ekologi. Cetakan ke-1. Edisi 2. Padang: Universitas Andalas. 